\title{
BULK COMPOSITIONS OF ULTRAMAFIC NODULES FROM THE MATSOKU PIPE AND THEIR RELATION TO KARROO BASALTS
}

By

K.G. Cox, J.J. Gurney and B. Harte

Studies have been carried out to determine whether any simple relationships exist between the bulk compositions of peridotitic nodules from the Matsoku Pipe and the Karroo basalts, which the pipe cuts. A small proportion of the nodules is comparatively rich in garnet and clinopyroxene and thus has more basaltic compositions than the majority, which is clinopyroxene- and garnet-poor ilherzolite. However none of the garnet-clinopyroxene-rich samples has a bulk composition which can give rise to Karroo basalt by any simple crystalliquid fractionation process (e.g. removal of olivine, orthopyroxene or both). Thus at present the proposition that such nodules might represent trapped Karroo liquids can not be proved.

An alternative hypothesis, that the garnet-clinopyroxene-rich nodules, many of which show coarse mineralogical banding, are variably sorted crystal cumulates associated with the extraction of basaltic liquids is perhaps more attractive. Only major element characters have so far been studied and amongst these the behaviour of $\mathrm{Na}$ seems to place considerable restraints on the types of relationship which may be postulated. $\mathrm{Na}$ is enriched in Karroo basalts by a factor of about 15 relative to the garnet-clinopyroxene-rich nodules. Even allowing for modest amounts of olivine fractionation at low pressures in the basalt magma this still leaves a ten-fold enrichment to be accounted for. Experimental melting of the nodules is clearly required to ascertain whether their partial melts have the required characteristics. 